\title{
Presenting Innovation Model In Mazandaran Province Education
}

\author{
Davood Hamednezhad ${ }^{1}$ \\ Vahid Fallah $2^{*}$ \\ Taraneh Enayati ${ }^{3}$ \\ 1, 2, 3Department of Educational Management, Sari Branch, Islamic Azad University, Sari, Iran \\ *Corresponding Author Email: davodhamed45@gmail.com
}

\section{Doi:10.5901/mjss.2016.v7n4s2p147}

\begin{abstract}
The general purpose of this study was to propose the innovation model in Mazandaran province Education. This study is applied in term of purpose and the methodology is descriptive of survey kind. The statistical population includes chiefs and deputies of Mazandaran province Education Organization and its 2653 schools managers. 338 people were selected as statistical sample using stratified -cluster random sampling and Cochran formula. A researcher made questionnaire containing 65 questions was used to gather data. Content and face validity of the questionnaire was approved by experts and its reliability was calculated OF 0.89 using Cronbach Alpha Coefficient. The results of structural equations showed significant and positive relationship between innovation variables in Education and organizational dimensions (organizational culture, administration style, human resources, technology, and organizational incentives) and educational dimensions (teaching methods, educational content and methods of students study). The results of confirmatory factor analysis confirmed the fitness of innovation model in Education Implementation is suggested in Mazandaran Province Education Organization.
\end{abstract}

\section{Introduction}

In today's changing and complex environment, Innovation is a critical factor for organizations to create value and sustainable competitive advantage. In fact, innovation means converting creativity and new ideas into action and results. The main support of innovation in all its aspects is to provide new ideas. Innovation often is resulted by deliberate seeking of new opportunities and this process begins with an analysis of these opportunities.

Today's organizations because of the spread of information and communication technologies is changing every moment and the necessity for continuity and survival lies in creativity and innovation; because innovation can provide a sustainable competitive advantage for them. For any organization, from a static to a dynamic state of change must keep their creative and innovative. (Moghimi and Ramezan, 2011, 356)

Innovation is process getting creative idea and to products, services and new ways of operation. Also, innovation is a practical and user-thoughts and new ideas of innovation, where information is presented in various ways. (Mihaela and Titan, 2014, 1043)

Educational Innovations from 1985 to 2001 has been increasing and now with the help of technology development, has become enriched. Experience of successful countries in the world have shown that short-term educational organizations while benefiting from the advantages of innovation, have created a strategic plan for its modernization. (Mota and Scott, 2014, 58) They have changed structure of the educational system to a flexible system of innovation by innovative strategies.

Managers of this educational systems, to win at the same time and in the future to have two separate games. First, try to improve your short-term competitive potential to increase their effectiveness and high performance are aware that this alone does not guarantee long-term success. Second, to achieve sustainable success in another game must be master of knowing when and where innovation is profound. (Weerawardena et al., 2006)

Process innovation in education include "understanding, the first step in the innovation process, full understanding of the issue. Solving the problems of education, it investigates the important task that needs to be made. Vision, insight and planning symbols is considered at this stage of development and the goals motivating activity is emphasized. Expectations creation to achieve desirable and feasible behavioral objectives, as a means to shape and reinforce positive attitudes to innovation activities, are essential.

Empowerment, innovation activities within the structures that are faced with strict controls, were not implemented and should be based on their motivation and commitment. Support, such as properties innovation is not immortal, so it is 
always accompanied by risk. "(Sam Khanian, 2005)

Innovation opens a window towards new opportunities and ensures a sustainable competitive advantage in organizations. When talking about innovation in education, changing the education system in general and changes in its components and implementation procedures are described in detail there. Of course this changes must consciously, purposefully and in order to improve the existing system and achieve optimal system.

Creating constructive changes in training communities, and sustainable innovations are radical, innovative range of organizations and training centers are numerous, so research on innovation in education is essential. (Weerawardena et al., 2006)

Toorani et al. (2012), in a study entitled "Global experiences in the field of educational innovations in terms of production methods, acceptance and implementation of innovation in public education." Showed that the current situation in Iranian education system is not suitable for implementation of the proposed model is not a ground for its implementation.

Seyyedi et al. (2012), showed that the correlation between technological innovation and innovation in organizations there and total quality management as a management philosophy and organizational culture can help to build and improve innovation in the organization to be effective. Bahrami et al (2011) showed that the relationship between human capital, structural capital and relational capital there is a significant relationship with innovation.

Senobar et al (2011) showed that each of the drivers of innovation (knowledge management, innovation management, IT management) significant positive influence in creating and enhancing innovation capacity in knowledgebased companies. Among these variables Technology Management and Knowledge Management had the highest coefficient.

Niknami et al (2009) showed that between creativity, organizational culture, organizational climate, organizational learning and knowledge management and the direct effect of positive and significant correlation with innovation in their school principals in Tehran. Gundry et al (2014), a study showed that students who have higher self-esteem and selfconfidence, more innovation. Teaching methods and creative thinking also plays an important role in the behavior of students.

Gorozidis and Papaioannou (2014), the study showed: Teachers more freedom to realize scientific innovations have had more success than groups that do not have autonomy. This means that policy makers should be through incentives, give teachers more freedom. Gündüz and Balyer (2014), in research, innovation needs of primary schools and they showed that the need for innovation in all aspects of innovation was moderate.

Pedaste et al (2014), in a study entitled "A Model of Innovative Schools: A Case Study in Estonia", strengthen partnerships between schools and universities studied systematic. This model four dimension training, professional improvement, training and research and development examined. The results showed that: synergies between these dimensions leads to innovation. Uzbek et al (2013) in a study on the results achieved in the field of human resource management, knowledge management is a positive feature and employees have a significant impact on creativity and innovation.

Koenigs et al (2007) study entitled "Views of teachers in Innovation: Implications for Instructional Design" Nonworking teachers with instructional designers examined and showed that student teachers independence, methods of study and productive learning are emphasized. The findings of this research is useful feedback for instructional designers; that is better when designing their collaboration with their teachers.

Nowadays organizations in the field of creativity and innovation of organizations responsible, education; because the major infrastructure and major education and development aspects of man's personality and opinions. Therefore, change and innovation in education is a necessity and requires the researcher interested in the state education system, aspects of the issue and take essential steps to improve the process. Therefore with regard to presentation, main question is: What is the model of innovation in education?

\section{Research Method}

In terms purpose of the present study is applied, and the method is descriptive survey. Statistical society were heads and deputy heads of departments and directors of the education schools of Mazandaran province, formed in 2653 that uses cluster random sampling method using a sample of 338 subjects were chosen. For data collection, a questionnaire was used with 65 questions in two dimensions (organizational and educational) and eight areas.

Tool face and content validity by experts and its reliability was calculated using Cronbach's alpha coefficient as 0.89. For the analysis of test data, exploratory factor analysis was used. According to the review and careful study and theoretical study of eight components for innovation in education were identified as Table 1. 
Table 1: Dimensions and components of innovation in education to provide model

\begin{tabular}{|c|c|c|c|c|}
\hline Questions & Researcher (years) & Component of innovation in education & Components & Row \\
\hline $1-8$ & Niknami et al (2009) & Innovation in organizational culture & \multirow{5}{*}{ Organizational } & 1 \\
\hline $9-16$ & Nickels (2004) & Innovation in education management style & & 2 \\
\hline $17-25$ & Bahrami (2011) and Kootras and Bootees (2013) & Innovation in human resources & & 3 \\
\hline $26-32$ & Seyyedi et al. (2012) & Technology Innovation & & 4 \\
\hline $33-40$ & Gorozidis and Papaioannou (2014) & Innovation in organizational incentives & & 5 \\
\hline $41-48$ & Gundry et al. (2014) & Innovation in teaching methods & \multirow{3}{*}{ Education } & 6 \\
\hline $49-57$ & Gundry et al. (2014) & Innovations in learning content & & 7 \\
\hline $58-65$ & Koenigs et al. (2007) & Innovation in methods for students & & 8 \\
\hline
\end{tabular}

\section{Findings}

\subsection{How is Innovation Model in education in Mazandaran province?}

Figure 1: Estimated standardized coefficients in the model organizationally
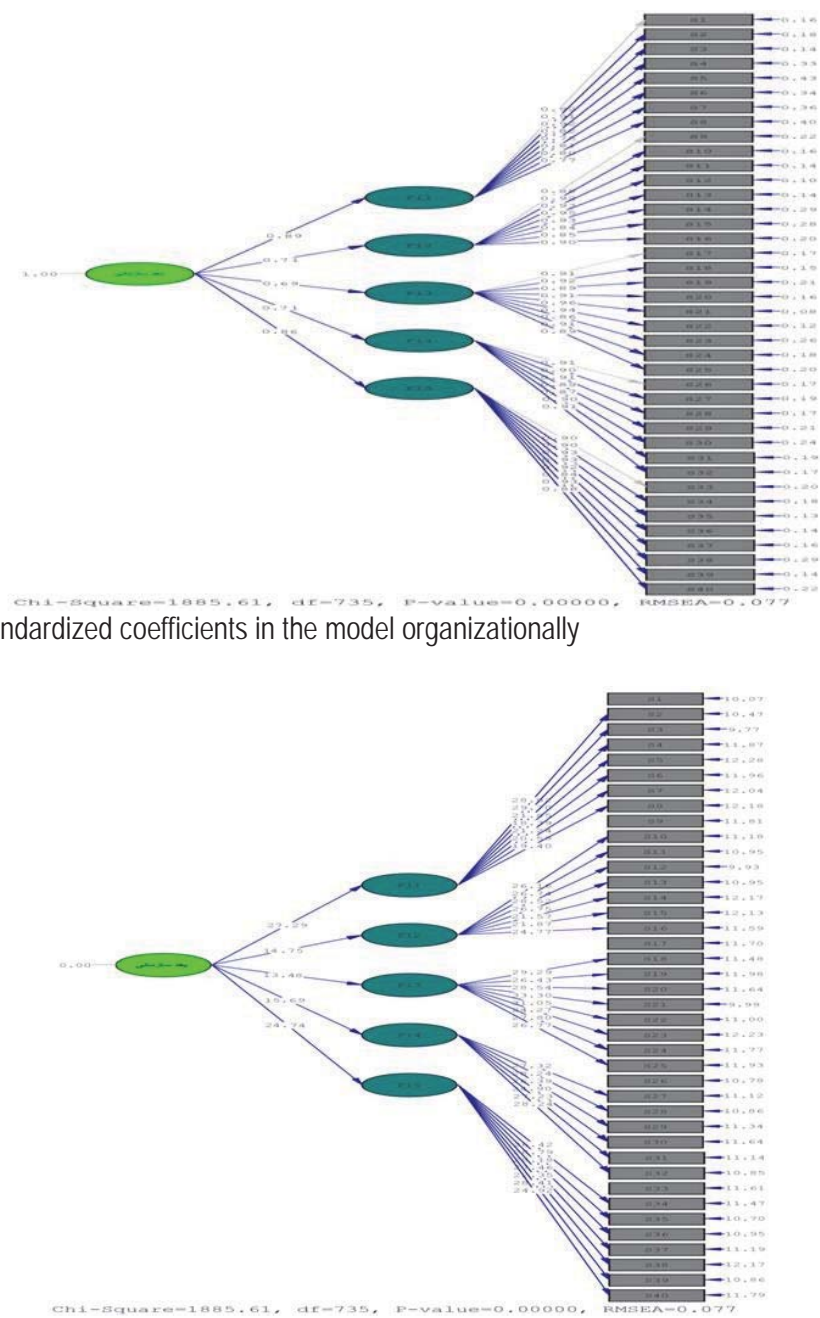

Figure 2: Estimated coefficients in the model t test 
Table 2: The results of confirmatory factor analysis to enterprise-wide significance dimension 0.05

\begin{tabular}{c|c|lc}
\hline Standardized coefficient & Statistic $\mathbf{t}$ & Variables & Row \\
\hline 0.89 & 27.29 & Innovation in organizational culture & 1 \\
\hline 0.71 & 14.75 & Innovation in education management style & 2 \\
\hline 0.69 & 13.48 & Innovation in human resources & 3 \\
\hline 0.76 & 15.69 & Technology Innovation & 4 \\
\hline 0.86 & 24.74 & Innovation in organizational incentives & 5 \\
\hline
\end{tabular}

Results diagrams 1 and 2 as well as confirmatory factor analysis in Table 2 show that there is a significant positive relationship between the organizational dimension and its components.

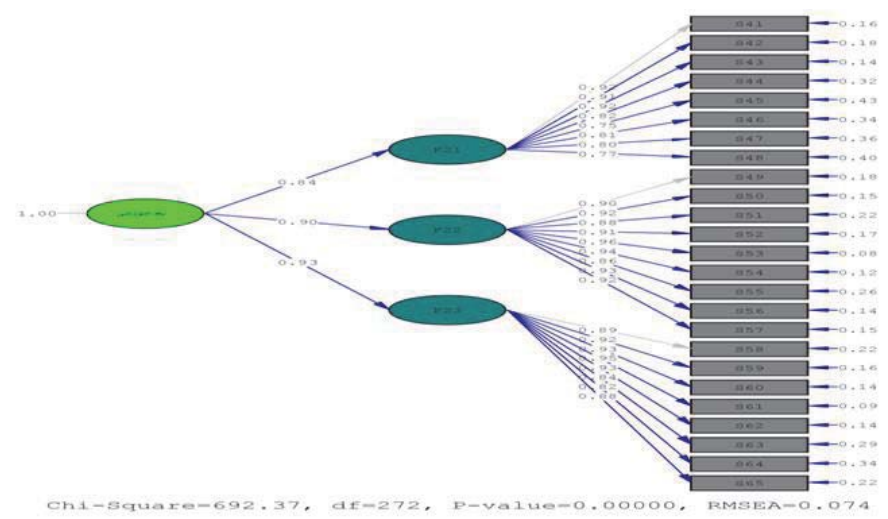

Figure 3: Estimated standardized coefficients in the Educational dimension model

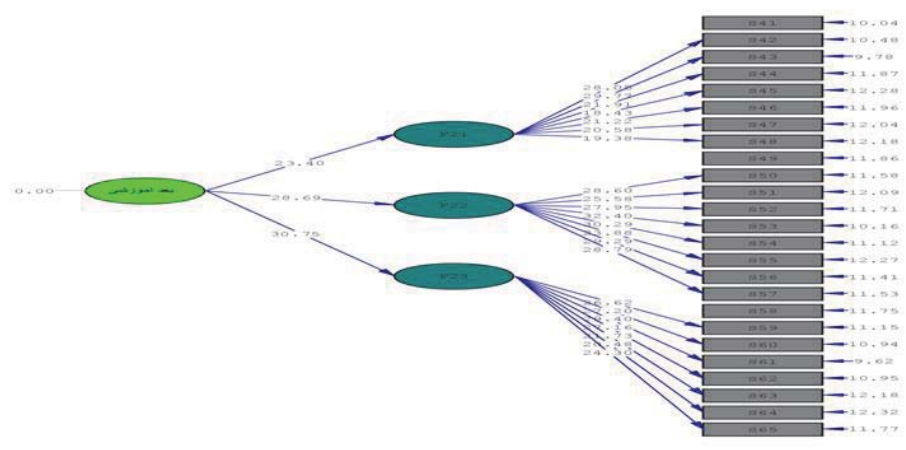

Diagram 4: Estimating of coefficient in the model t test

Table 3: Results of confirmatory factor analysis results for dimension significant level training 0.05

\begin{tabular}{c|clc}
\hline Standardized coefficient & Statistic $\mathbf{t}$ & Variables & Row \\
\hline 0.84 & 23.40 & Innovation in teaching methods & 1 \\
\hline 0.90 & 28.69 & Innovations in educational content & 2 \\
\hline 0.93 & 30.75 & Innovation in methods for students & 3 \\
\hline
\end{tabular}

Results of diagrams 3 and 4 as well as confirmatory factor analysis in Table 3 and there is a significant positive relationship between Educational dimension and its components. 


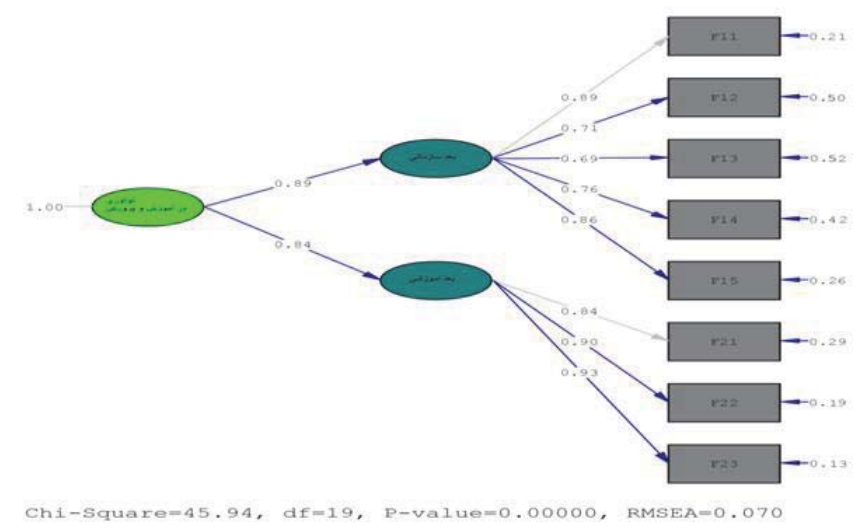

Diagram 5: Standardized beta coefficient in the model

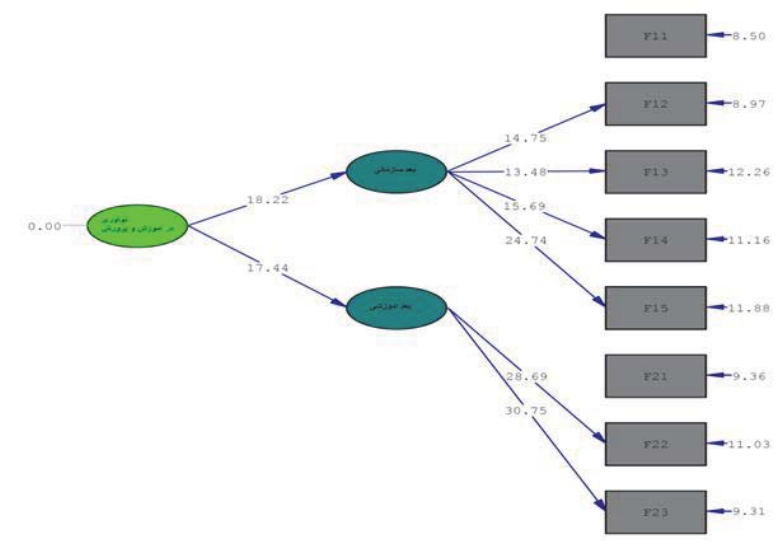

Diagram 6: Estimating of coefficient in the model $t$ test

Table 4: The results of confirmatory factor analysis in significant level of 0.05

\begin{tabular}{c|c|l|c}
\hline Standardized coefficient & Statistic $\mathbf{t}$ & Variables & Row \\
\hline 0.89 & 18.22 & Organizational dimension & 1 \\
\hline 0.84 & 17.44 & Educational dimension & 2 \\
\hline
\end{tabular}

Diagram 5 and 6 show confirmatory factor analysis in Table 4, based on standardized coefficients between organizational dimension and innovation in education with loading factor 0.89 and with the educational dimension loadings 0.84 . Also in the $95 \%$ confidence level and measurement error $\alpha=0.05$ with degrees of freedom 19 for both organizational and educational dimensions $t>1.96$ was calculated, so there is a significant positive relationship between innovation in education with organizational and educational dimensions .

Structural equation modeling study are as follows:

Organizational dimension $=0.89^{*}$ innovation in education, variance error $=0.21$, determination coefficient $=0.79$

(0.024) (0.032)

18.226 .54

Educational dimension $=0.84 *$ innovation in education, variance error $=0.19$, determination coefficient $=0.7$

(0.028) (0.054)

$17.44 \quad 5,34$

The above equation structural model suggests that organizational dimension of innovation in education variable 
(impact factor 0.89 and covariance error 0.24 and $t=18.22$ ), the error variance 0.21 and $t=6.54$ ) accept direct and significant impact. Educational dimension of innovation in education (impact factor 0.84 covariance error 0.054 and $t=17.44$ the error variance of 0.19 and $t=5.34$ ) accepts significant effect directly.

\subsection{What is the degree of appropriateness innovation in education?}

Table 5: Results of the findings of the measurement model at a significance level 0.05

\begin{tabular}{lccc}
\hline Index & Desirable value & Calculated value & Result of test \\
\hline Estimates of the degree of freedom chi-Square (X/DF) & $<3.00$ & 2.42 & Approved \\
\hline The estimated root mean square errors (RMSEA) & $<0.08$ & 0.070 & Approved \\
\hline The root mean square residual (RMR) & $<0.05$ & 0.047 & Approved \\
\hline Goodness of fit index (GIF) & $>0.90$ & 0.92 & Approved \\
\hline Model fitting index (NFI) & $>0.90$ & 0.94 & Approved \\
\hline Not normal fit index (NNFI) & $>0.90$ & 0.92 & Approved \\
\hline Comparative fit index (CFI) & $>0.90$ & 0.95 & Approved \\
\hline Adjusted goodness of fit index (AGFI) & $>0.90$ & 0.83 & Rejected \\
\hline Incremental fit index (IFI) & $>0.90$ & 0.95 & Approved \\
\hline Relative fitness index (RFI) & $>0.90$ & 0.91 & Approved \\
\hline
\end{tabular}

Chi-square test results in Table 5 shows that the ratio of the degrees of freedom is equal to 2.42 , because the index is less than 3 the suitability of the model, so model is a good fit. Also, estimated to approximate root mean square errors is 0.070 in the index, values less than 0.08 reflect the suitability of the model.

Good parameters of the model were as root mean square residual index 0.047 , goodness of fit index 0.92 , model fit index0.94, the index did not fit the norm 0.92, comparative fit index0.95, goodness of fit index adjusted 0.83 , incremental fit index 0.95 and comparative fit index is 0.91 .

In the above indicators, with the exception of adjusted goodness of fit index, all values were above 0.9 indicates a perfect fit model. Therefore, the proposed model as appropriate, and the relationship between key variables and dimensions together is positive and significant.

\section{Conclusion}

Innovation opens a window towards new opportunities and ensures a sustainable competitive advantage in organizations. In education, when speaking of innovation, changing the education system in general and changes in its components and implementation procedures are described in detail. Innovation in education organizations emanating from an idea or behavior that the overall environment organization.

Creating constructive changes in teaching and training communities, and sustainable innovations are radical, innovative range of organizations and training centers are numerous, so research on innovation in Education is essential. Accordingly, the purpose of this study to develop a model of innovation in Education in Mazandaran province.

Structural equation modeling (SEM) results indicated that between innovation in Educational \& and organizational dimensions (organizational culture, administration style, human resources, technology, and organizational incentives , teaching methods, educational content and methods of students study ), there is significant positive correlation. Also results of confirmatory factor analysis, fitness model innovation in education approved.

This finding is consistent with research findings Seyyedi et al. (2012), Bahrami et al (2011), Senobar et al (2011), Niknami et al (209) in the interior and research results Gundry et al (2014), Gorozidis and Papaioannou (2014), Gündüz and Balyer (2014), and Koenigs et al (2007) abroad, therefore suggest that managers and directors of education with scientific and coherent planning to institutionalize innovation dimensions and components, in Education \& Training in the province after deciding to browse through the transformation and modernization of the education system.

\section{References}

Bahrami, Susan; Rajaeepour, Saeed, Agha Hosseini, Taghi; Bakhtiar Nasr Abadi, Hassan Ali and Yar Mohammadian, Mohammad Hossein. (2011) analyze the relationships of intellectual capital and organizational innovation in higher education. Journal of Research and planning in higher education, 61, Pp50-27.

Toorani, Heidar, Aghaie. Amir and Manteghi, Morteza. (2012) global experiences in the field of educational innovation in terms of 
production methods, acceptance and implementation of innovation in public education. Journal of Educational Innovations, Volume XI, Issue 43, pp. 7-41

Sam Khanian, Mohammad Rabi. (2005) creativity and innovation in educational organizations. Tehran: Publication of specialized media

Seyyedi, Seyyed Masoud; Shahidi, Nima and Sharafi, Rasool. (2012) the feasibility of applying TQM to create innovation in the areas of education quad city of Shiraz. New Approaches in Educational Administration Quarterly, Issue 10, Pages 55-70

Senobar, Nasser; Salmani, Behzad and Tajvidi, Mina. (2011) stimulatory effect of innovation on science-based innovation capacity of companies. Journal of Science and Technology Policy, Volume IV, Number 2, Ss104-91

Moghimi, Seyed Mohammad and Ramezan, Majid. (2011) Principles of organization and management. Journal of Management, Tehran: Rah Dan

Niknami, Mostafa, Taghi pour Zahir, Ali, Delavar, Ali and Ghaffari Mojallaj, Mohammad. (2009) causal model innovation design and evaluation of educational leaders in Tehran. New Approaches in Educational Management, Volume II, Issue 5, Pages 28

Gorozidis, G., \& Papaioannou, G. (2014). Teachers' motivation to participate in training and to implement innovations. Teaching and Teacher Education, 39, 1-11.

Gundry, Lisa K., Ofstein, Laurel F., \& Kickul, Jill R.. (2014). How creativity skills in entrepreneurship education influence innovation in business. The International Journal of Management Education, 12(13), 529-538.

Gündüz, Yüksel., \& Balyer, Aydın. (2014). Examining Innovation Needs of Primary Schools: Teachers. Perceptions Procedia - Social and Behavioral Sciences, 116(21),139-143.

Könings, Karen D., Brand-Gruwel, Saskia., \& van Merriënboer, Jeroen J.G. (2007). Teachers' perspectives on innovations: Implications for educational design. Teaching and Teacher Education, 23(6), 985-997.

Mihaela, M., \& Tiţan, E. (2014). Education and Innovation in the Context of Economies Globalization. Procedia Economics and Finance, $15,1042-1046$

Mota, R., \& Scott, D. (2014). Education and Innovation. Education for Innovation and Independent Learning, 5, 55-71.

Ozbag, G. K., Esen, M., \& Esen, D. (2013). The Impact of HRM Capabilities on Innovation Mediated by Knowledge Management Capability. Procedia-Social and Behavioral Sciences, 99, 784-793.

Pedaste, Margus., Pedaste, Küllike., Lukk, Karin., Villems, Pille., \& Allas, Raili. (2014). A Model of Innovation Schools: Estonian Casestudy. Procedia - Social and Behavioral Sciences, 112(7), 418-427.

Weerawardena, J., Ocass, A., \& Julian, C. (2006). Does industry matter? Examining the role of industry structure and organizational learning in innovation and brand performance. Journal of business research, 59(1), 37-45. 